\title{
ENRICHMENT OF ONLINE AND PHYSICAL COLLABORATION
}

\section{ABSTRACT}

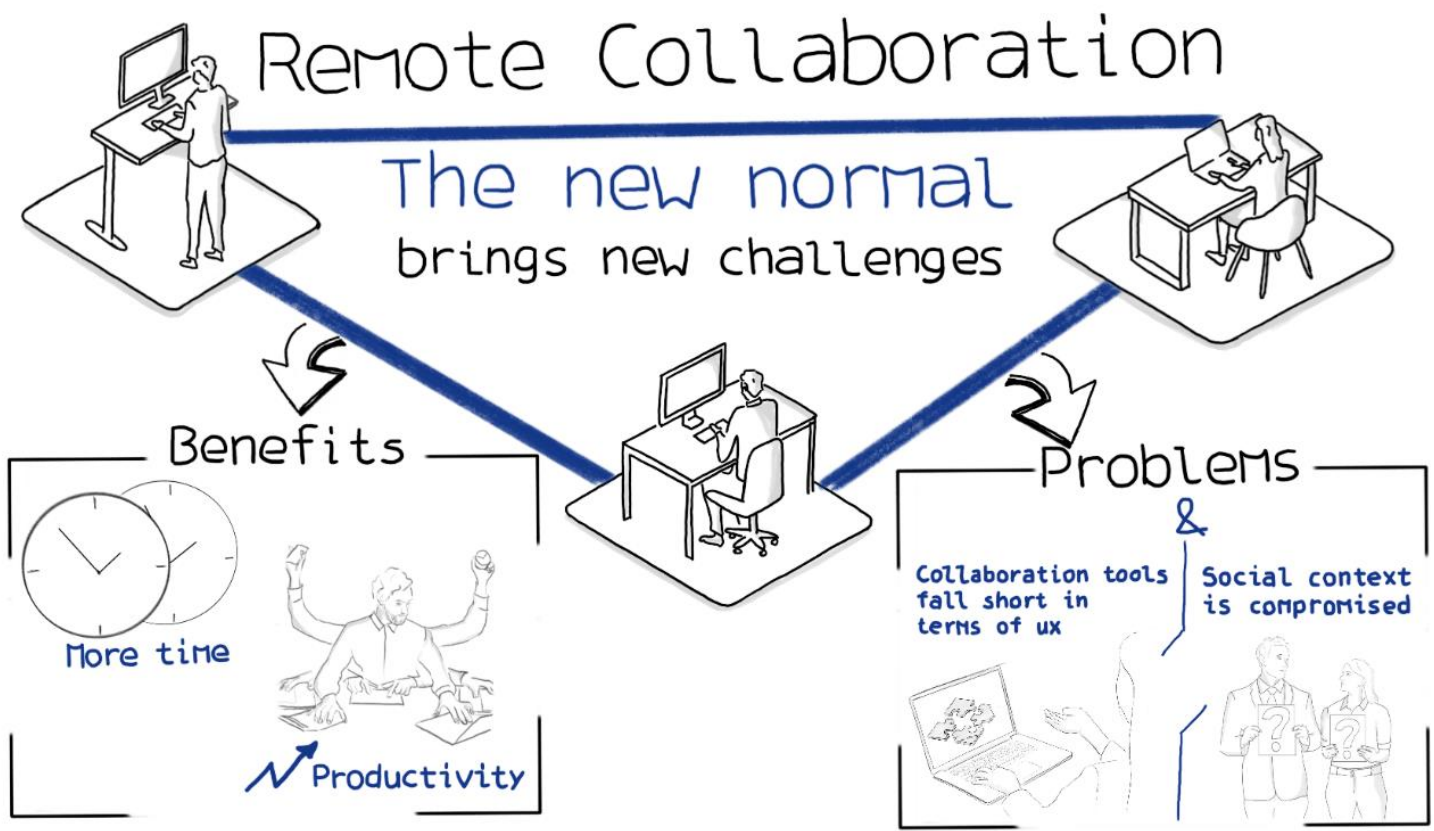

Prolonged online collaboration decreases employee productivity. Furthermore, the initial productivity gains from telecommuting are lost over time, and teams see their efficiency and effectiveness decline even with sustained remote collaboration.

Study methods

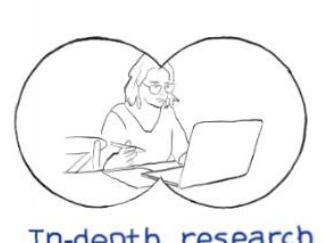

In-depth research

8

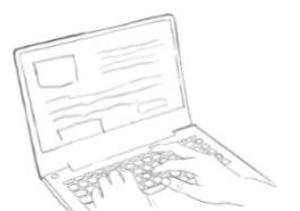

\& Desk research

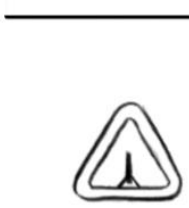

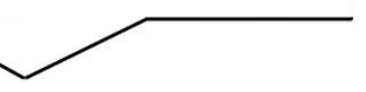

Major pain points of online collaboration

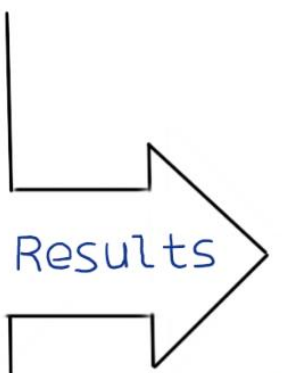

Design requirements and specifications

The current study evaluates the underlying pains and gains of prolonged remote collaboration. In addition, information from relevant studies like behavioural science and new technologies are explored. Based on interviews, observation and co-creation, opportunities are listed to inspire and provide direction for innovation in a hybrid work environment.

Keywords: Remote working, collaboration, hybrid working, social connection, employee experience 


\section{INTRODUCTION}

The prolonged period of enforced lockdown is, for site-independent collaboration, a unique research experiment from which much can be learned [1,2].

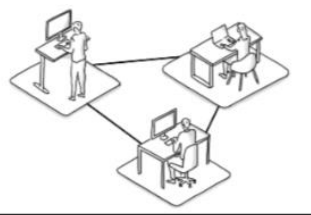

\section{The unstoppable rise of a new way of collaboration}

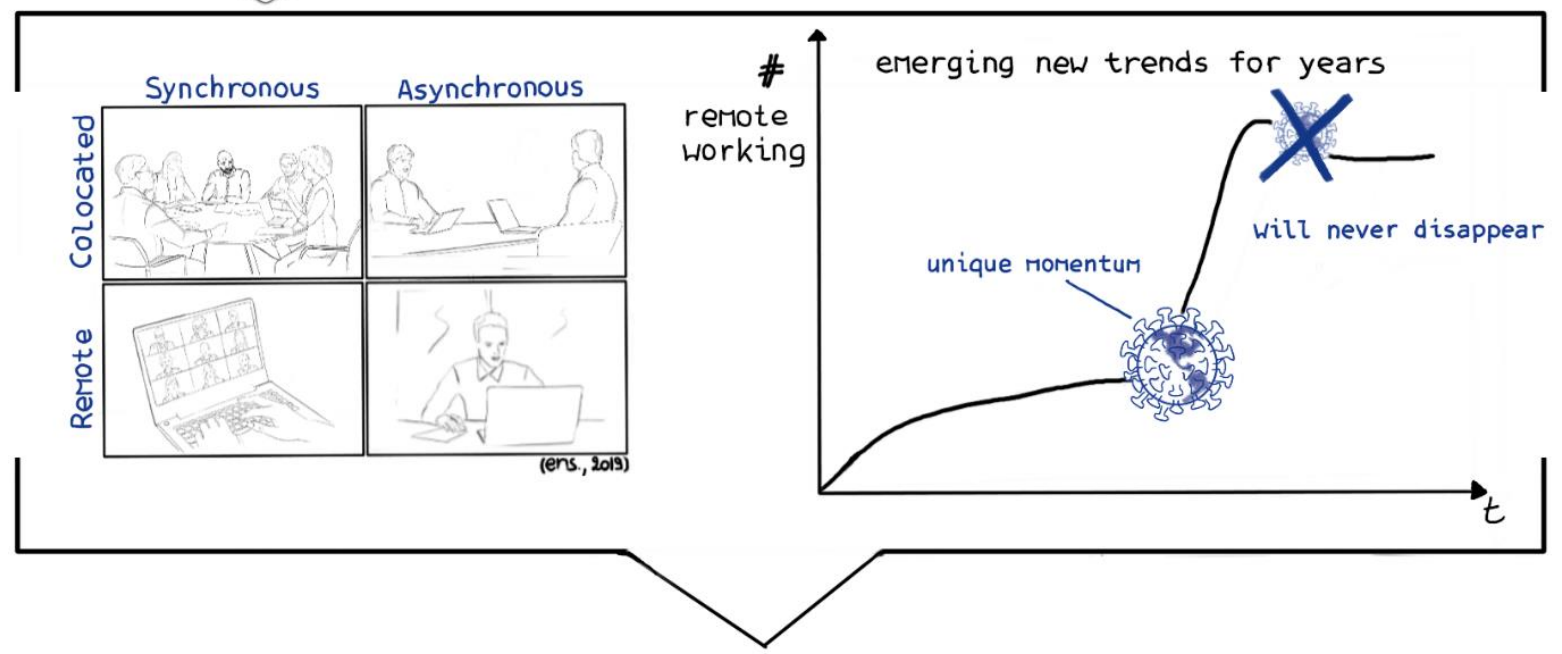

\section{still remains a challenge}
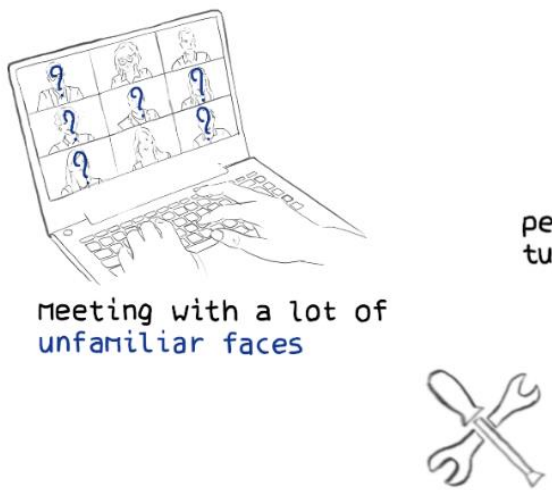

technical hiccups
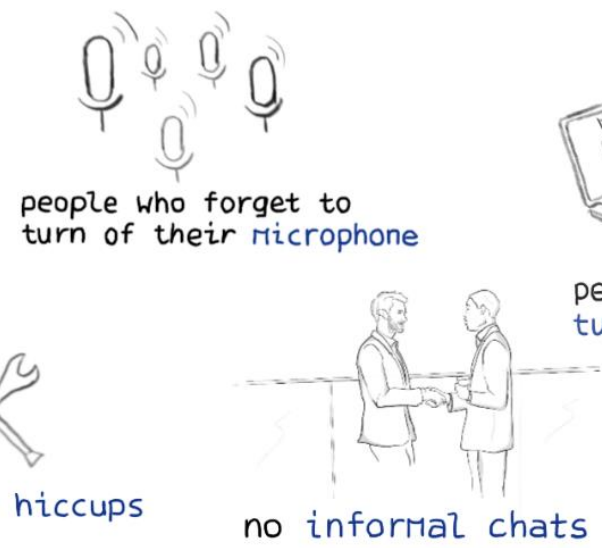

Therefore, the question remains: Are all these obstacles going to be eliminated in the near or distant future? Several technical geniuses (Cisco Webex, UGent, Zoom, etc.) are already taking up the challenge of transmitting non-verbal communication through the virtual world.

\section{Challenge}

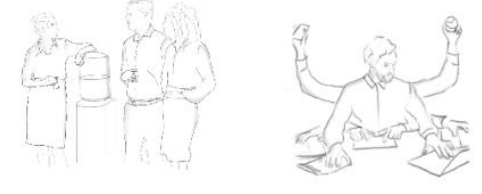

Organizations and developers face the challenge: "How can a new generation of remote online collaboration tools integrate new technologies and functionalities to reverse the declining productivity curve of long-term remote work and restore social cohesion within remote teams?" 


\section{STATE OF THE ART}

Teleworking has been increasing for a long time and has been part of the strategy of many companies to optimize work-life balance and office layout. However, no one suspected that the COVID pandemic would so quickly and abruptly revolutionize remote working. And yet, today, companies worldwide are facing the challenge of permanently integrating and properly organizing remote collaboration. Those who make a strong commitment to integrate this way of working will gain competitive advantage [3]. As a matter of fact, trends predict that the workplace will no longer be either physical or digital. The need for an integration of online and physical world is stronger than ever [4-8].

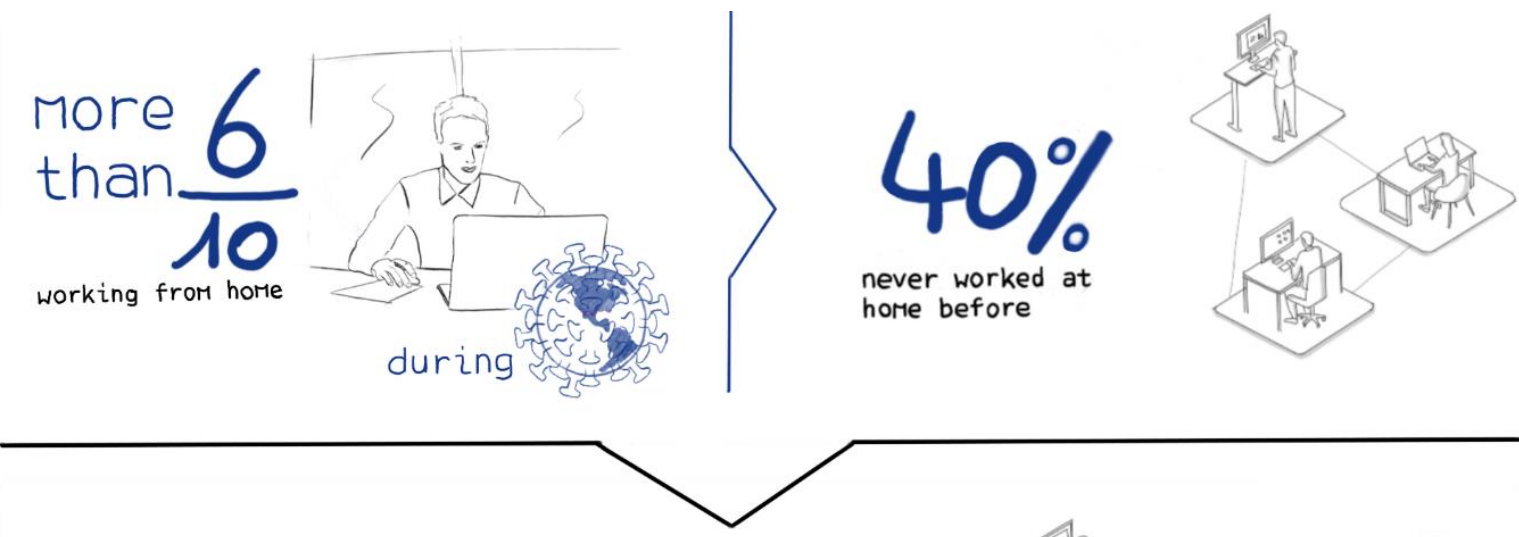

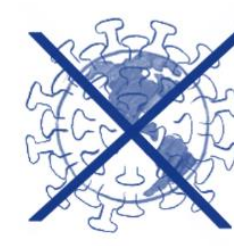

after

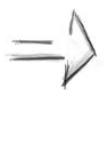

willing to telecommute

1-3 days/week
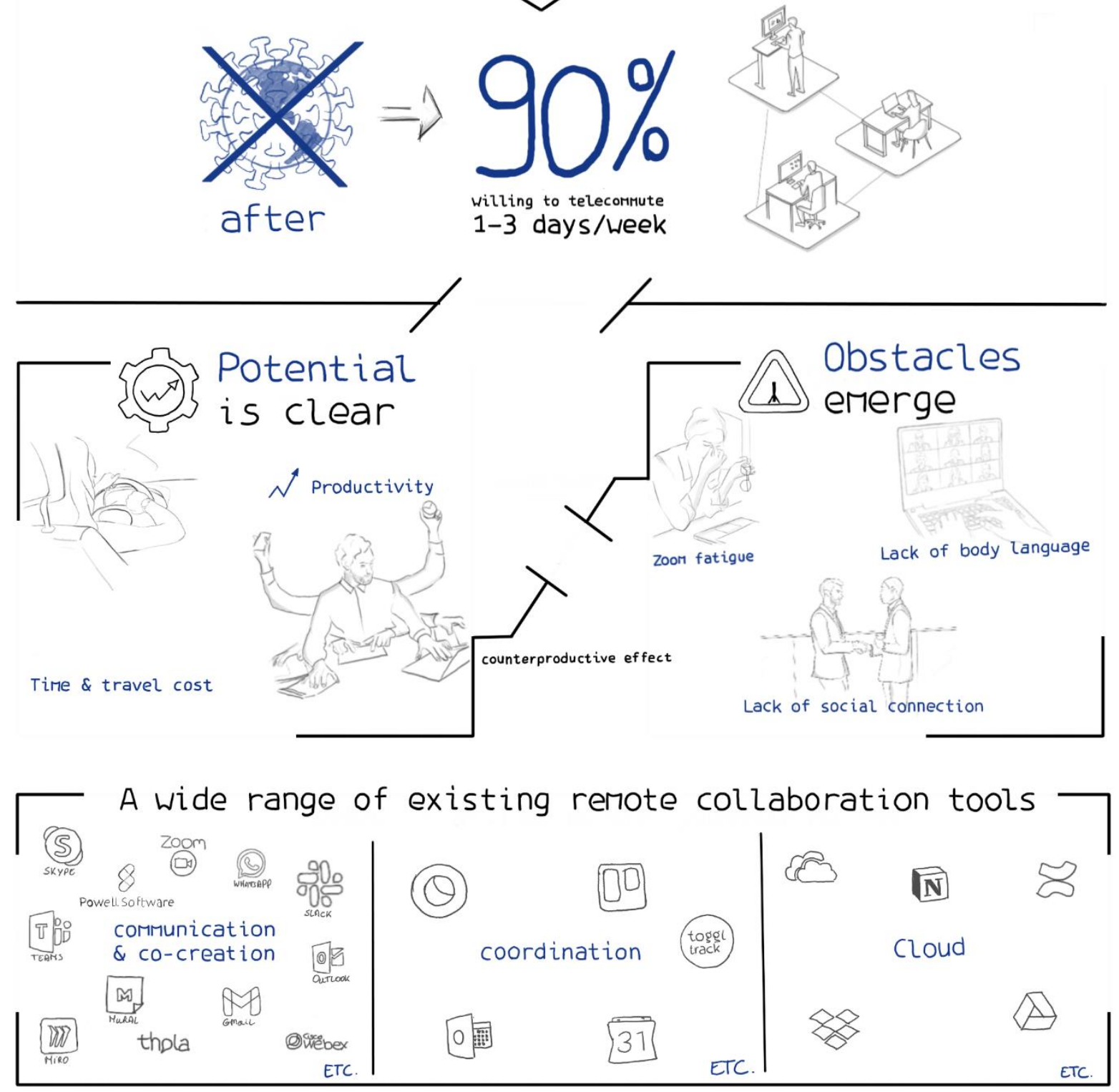


\subsection{Promising new technologies open new possibilities}

Disruptive innovation requires a creative process and an open mind for new technologies and their possible applications: artificial intelligence (AI), deep learning, natural language processing (NLP), machine body language recognition, sentiment analysis, holograms, virtual reality (VR), augmented reality $(\mathrm{AR}), \ldots$ open up unknown possibilities.

Yet, there are still a lot of opportunities waiting to be explored by designers who think in an interdisciplinary way, who discover new application domains for innovative technologies and who search for solutions based on a well-understood view of the problem and an open and broad perspective of what is happening in these new fields. Desk research and expert interviews helped define the possibilities of these technologies for future innovation [9-16].
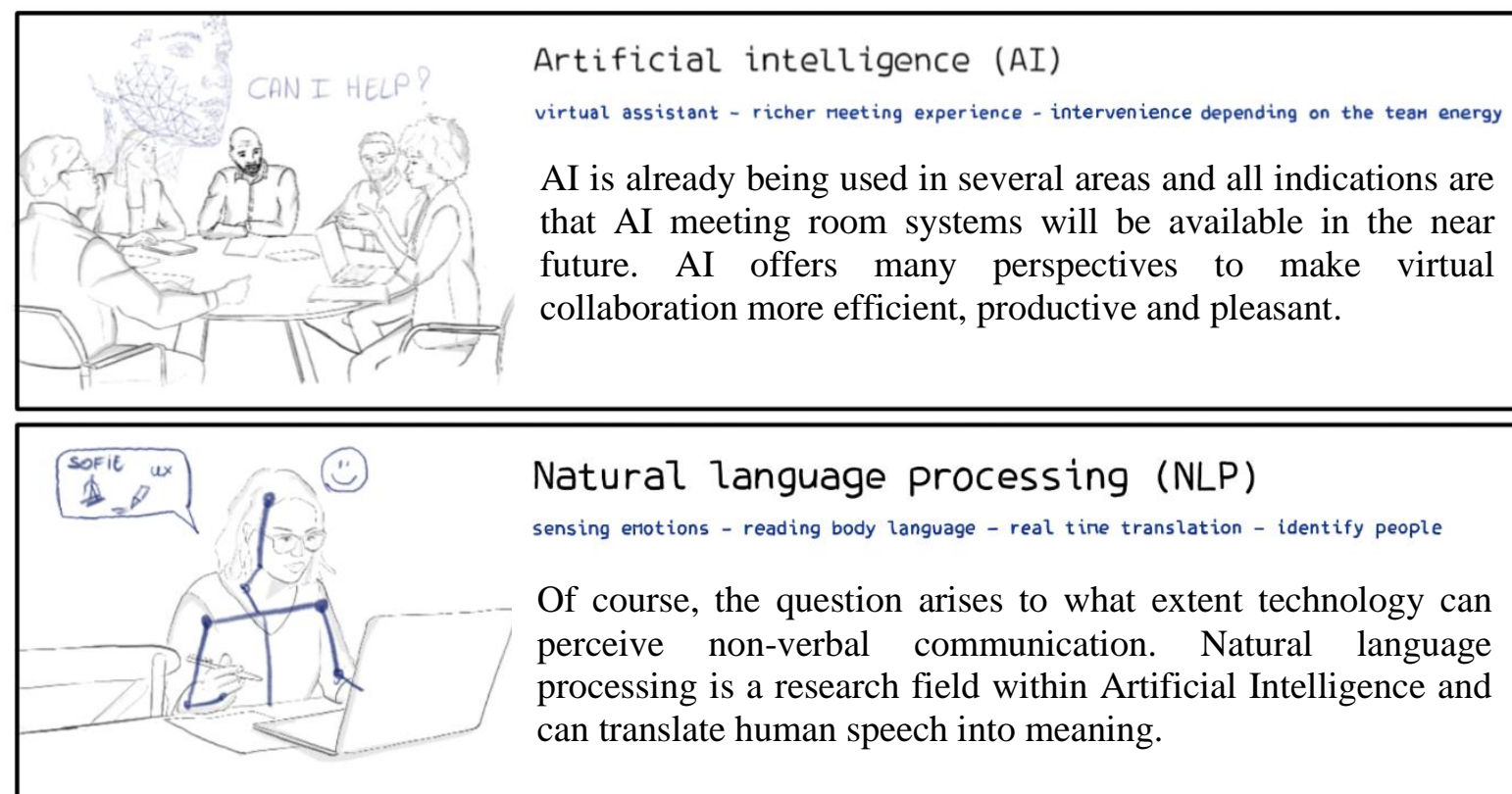

\section{Hologram technology}

Holoportation allows mixed-reality devices (including the Hololens) to see $3 \mathrm{D}$ projections of people in other locations. It is even possible to communicate with each other just as they communicate in the same physical space. However, it is only an approximation of reality and still quite expensive. Experts still envisage private use of this technology in the near future.

\subsection{The importance of behavioural psychology}

Astrid Groenewegen (2020) argues that team behaviour is the single most important parameter that directly influences and determines whether a team makes it or not and this is independent of the team's location. Therefore, the emerging behaviours during remote working were examined and the pains and gains involved carefully analysed. It is very important to realize that employees do not engage themselves purely for the work itself. People use the work context to fulfil certain personal needs. Ideally, future designs will help fulfil these needs [2]. 


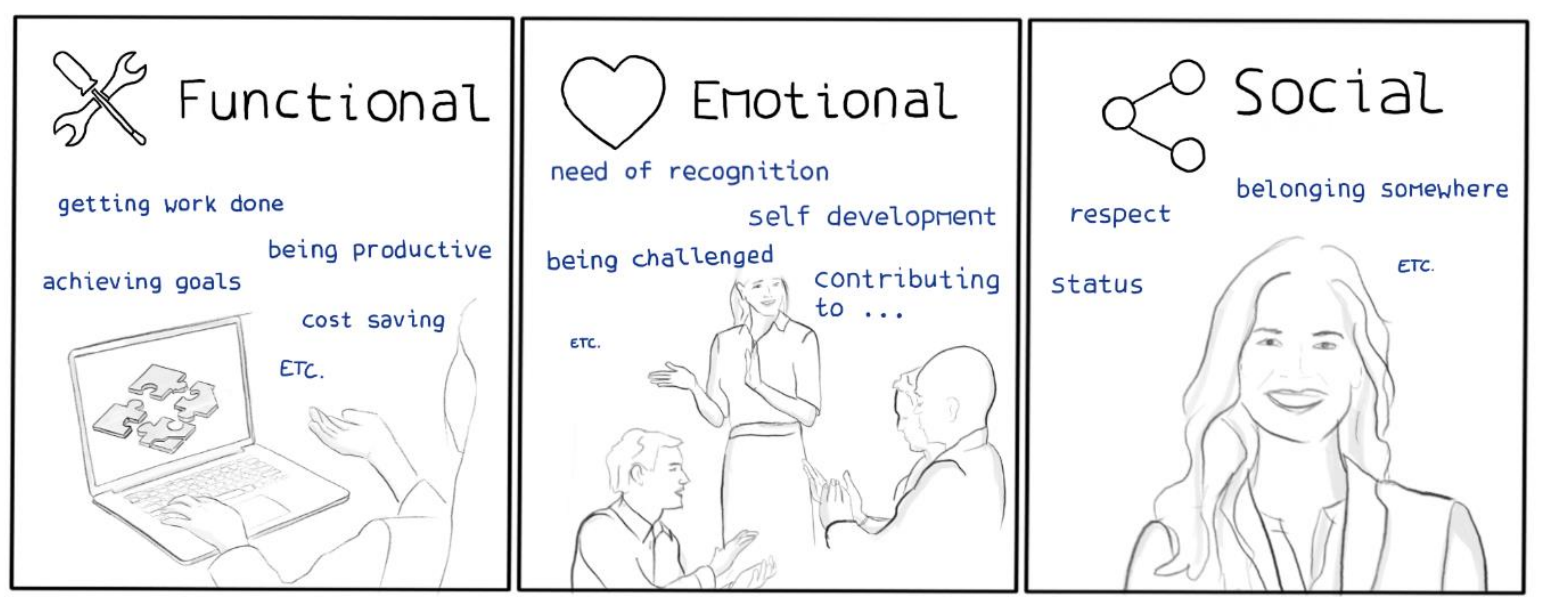

It is clear that people strive for social achievement and social connectedness. However, these desires are impossible to fulfil without social interaction. Additionally, social well-being appears to be highly dependent on personality factors. Research points to the importance of understanding the nuances associated with different personalities to fulfil the individual needs of employees as an organization. It is the interaction between environmental factors and personality traits that contribute mainly to people's productivity and well-being [17-19].

\section{RESEARCH METHODS}

The purpose of the study is to discover the common practices and the obstacles people encounter in the dayto-day remote collaboration practice and to gain insight into the underlying needs people experience when working remotely.

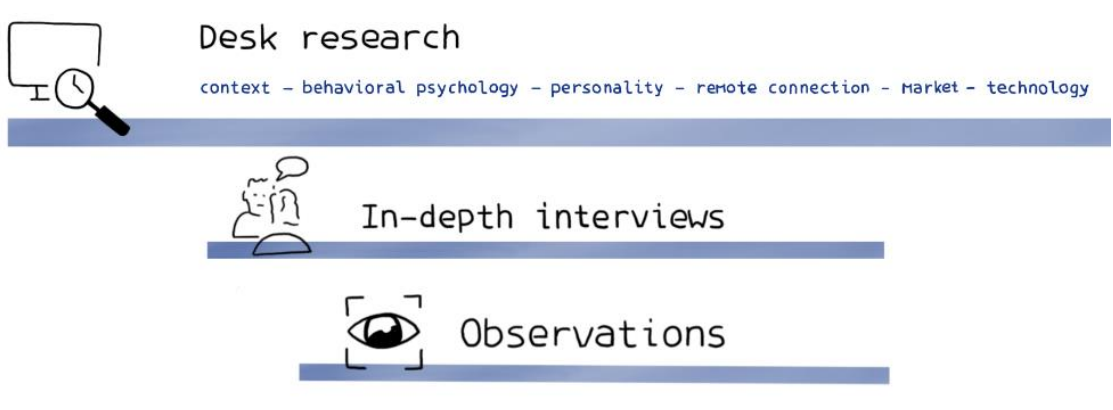

We firstly performed in-depth qualitative research using close observation and structured in-depth interviews to detect the common practices and the obstacles people encounter in a daily practice. Also, to gain a broader insight into the underlying needs that people experience when working remotely. The diversity of respondents ensures that not only the needs and obstacles of only one specific discipline are magnified, but also the universal deeper insights into experiences of distance working.

Several themes were questioned, for example: personal experiences, concentration level, working with digital tools and software, contact with colleagues, motivation, mental well-being, and more.

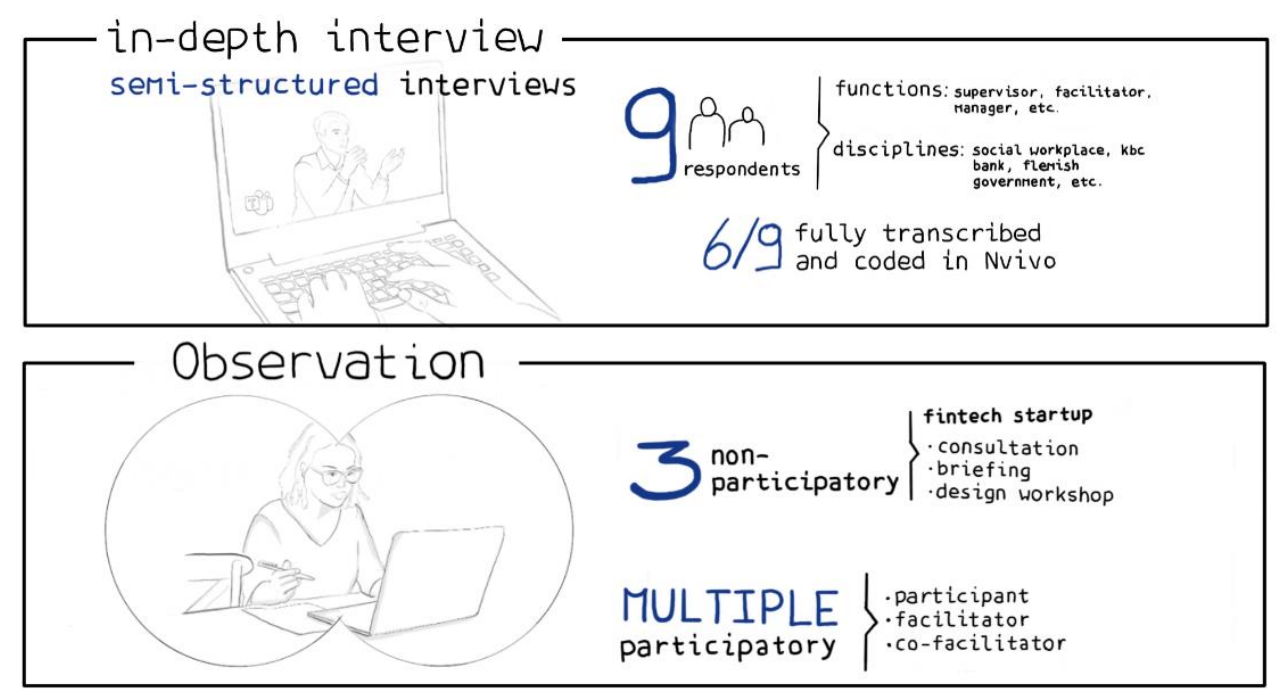




\subsection{Results of in-depth interviews and observations}

The visualization below shows an overview of the results divided into respectively the functional experiences and the social aspects. Six out of nine interviews were completely transcribed and coded in Nvivo. The large numbers in the figures indicate the number of topic citation. The small numbers indicate in how many of the interviews this topic was addressed by the respondent himself. For example: at least 30 times in 6 out of 6 interviews respondents mention the lack of human interaction.
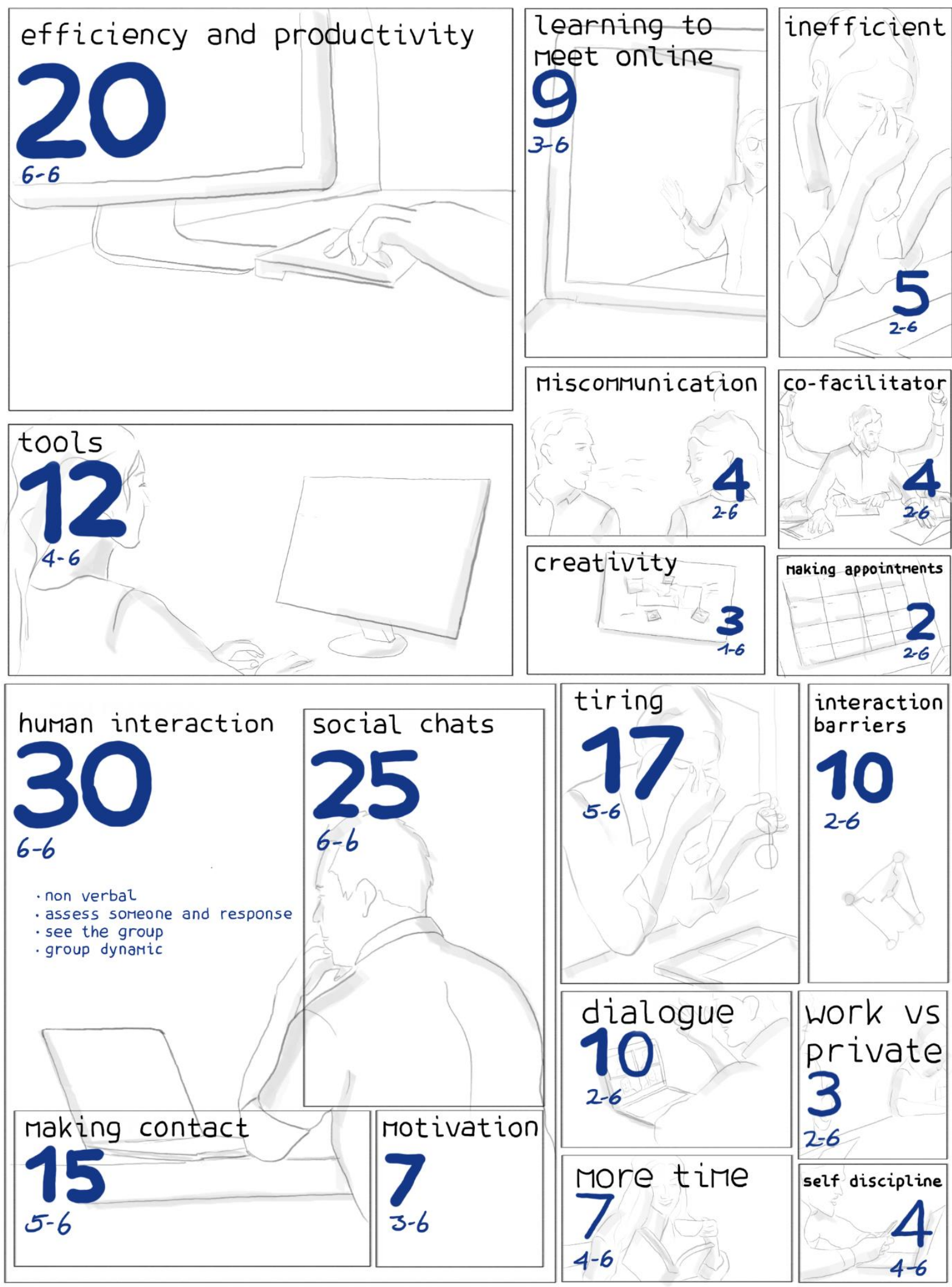

barriers

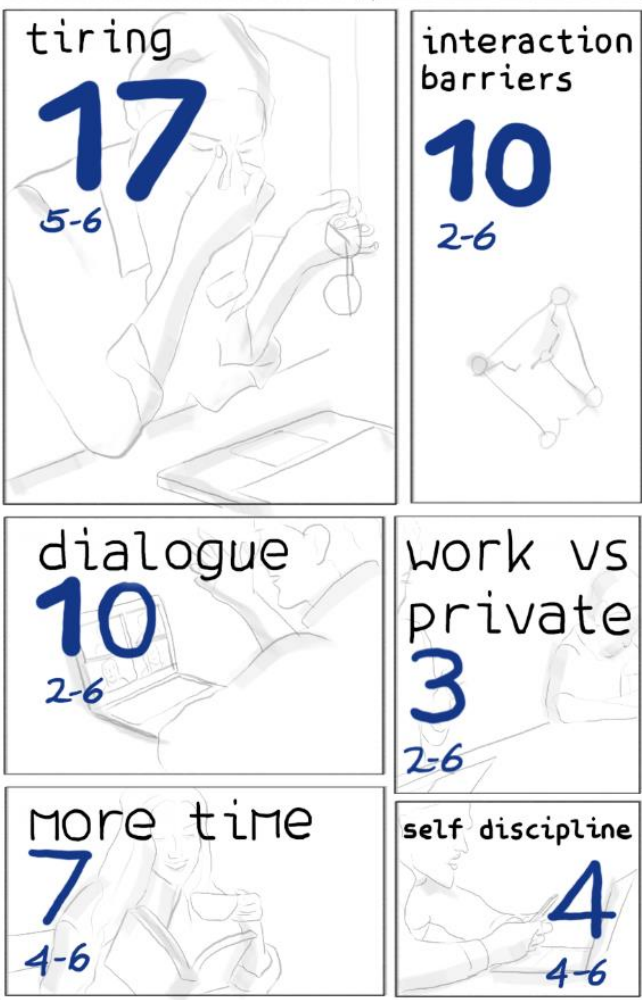

$2-6$

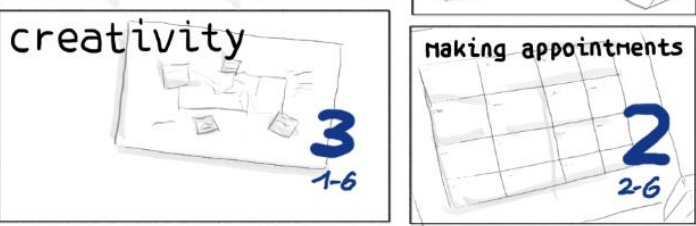




\subsection{Clear findings from the field research}

Even though people have been forced to work remotely for months, the observations make it clear that they still have not mastered the basics of online collaboration. In every co-creation session, echoes occur because of too many active microphones. In addition, countless times people report that the quality of the meeting is not good, then rather consider that they better turn off the video for reduced bandwidth. People are also reluctant or even downright unwilling to use new technologies.

Finally, it is notable that participants are very demanding and expect that every online session will run smoothly while in practice technical problems are unfortunately unavoidable.

To conclude, the in-depth user analysis provides numerous insights on the concrete perceived advantages and disadvantages of remote collaboration. The identified pain points of online collaboration can be divided into two major themes, each covering specific design challenges:

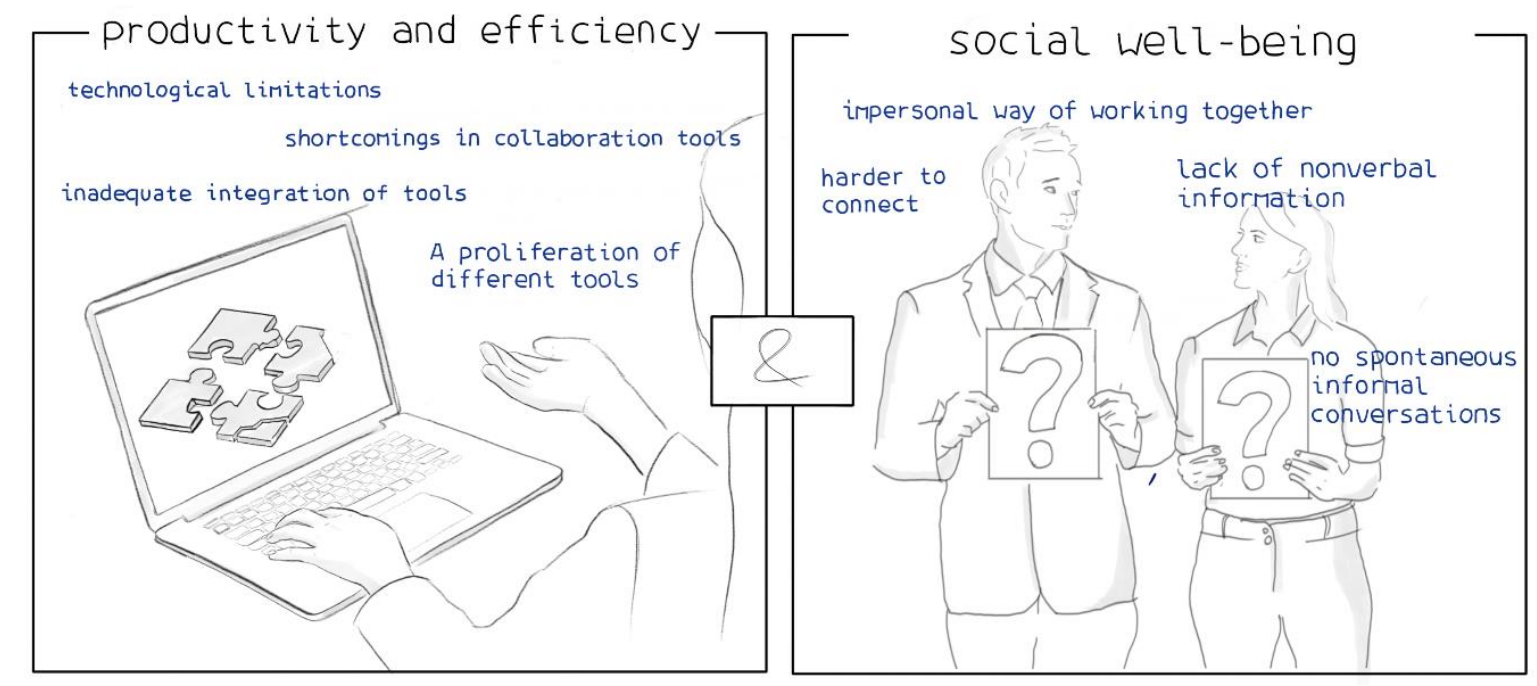

\section{RELEVANCE FOR PRACTITIONERS AND DESIGN TEAMS}

Based on prior research, three relevant design challenges were defined. Two of these challenges relate to the theme of social well-being. Our research reveals that the lack of social contact, informal conversations and non-verbal information are the most important problems.

If one wants to design for a positive impact related to hybrid working, these challenges are a starting point to make a difference.

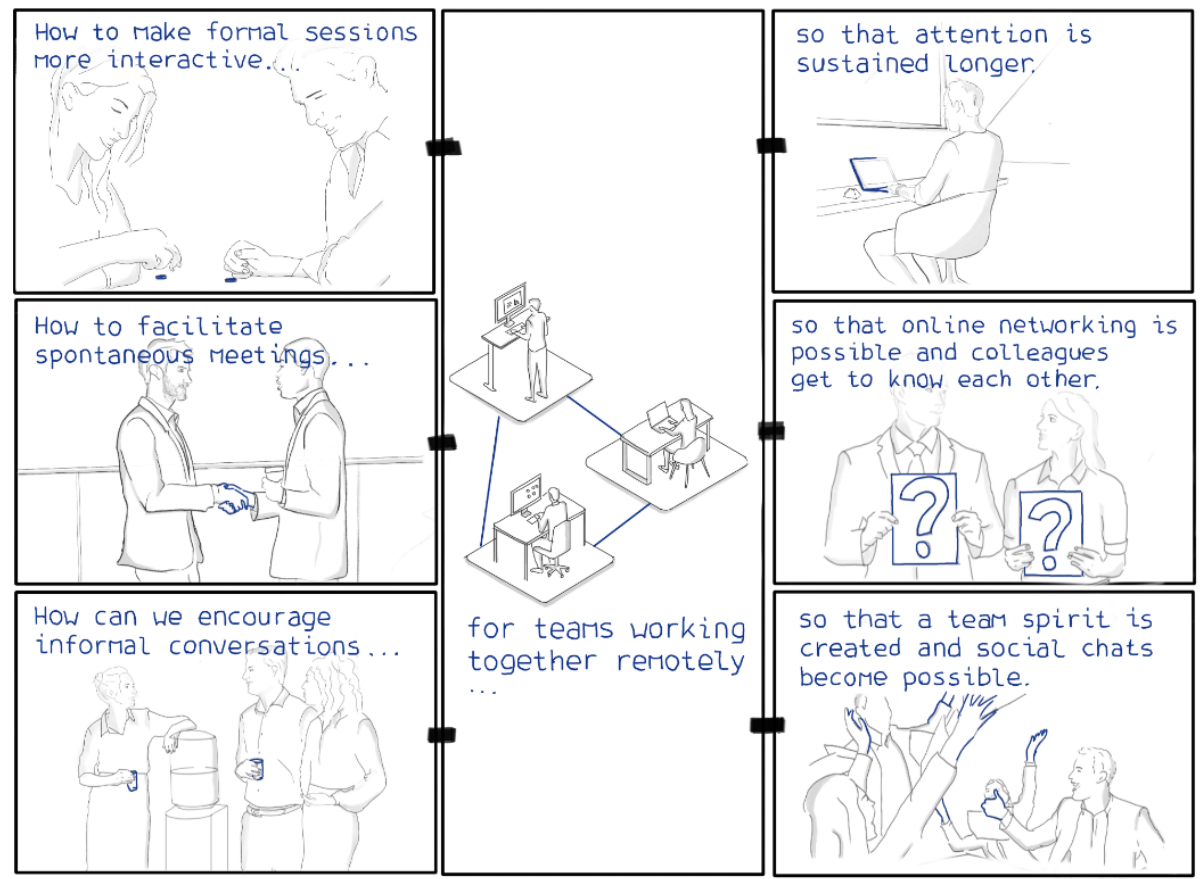




\subsection{Improvements for online collaboration}

Co-creation sessions with remote workers were conducted to validate the most common desires. This has resulted in a clear definition of some social shortcomings and needs for remote collaboration.

\begin{tabular}{|c|c|c|}
\hline Spontaneous encounter & Joint breaks & Before \\
\hline $\begin{array}{l}\text { This is a meeting you had not } \\
\text { planned, and you do not know } \\
\text { in advance with whom. It is } \\
\text { important that such meetings } \\
\text { are completely non-committal. } \\
\text { The resulting conversation is } \\
\text { mainly informal and is sincere, } \\
\text { inspiring, refreshing, ... }\end{array}$ & $\begin{array}{l}\text { Human contact is strong during } \\
\text { shared breaks. Being able to } \\
\text { blow off steam together creates } \\
\text { connection and a relaxing } \\
\text { feeling. } \\
\text { A joint break should be as } \\
\text { spontaneous as on the work } \\
\text { floor: there should be no rules, } \\
\text { no obligations but it should } \\
\text { have a loose - relaxing } \\
\text { atmosphere. }\end{array}$ & $\begin{array}{l}\text { After a meeting, workshop, etc. } \\
\text { time for "after" chats should be } \\
\text { offered. A formal meeting in the } \\
\text { virtual world often ends abruptly. } \\
\text { After-briefings should encourage } \\
\text { the exchange of informal } \\
\text { information. } \\
\text { In addition, before-and-after } \\
\text { conversations should take their } \\
\text { place as the transitional phase } \\
\text { between work and private life that } \\
\text { commuting entails in physical work } \\
\text { contexts. }\end{array}$ \\
\hline Communication & \multicolumn{2}{|c|}{$\begin{array}{l}\text { Online communication for a social context must be clearly } \\
\text { different from formal conversations such as meetings. Therefore, } \\
\text { another zoom-call using the same computer screen in the same } \\
\text { room will not suffice. In addition, this communication must be } \\
\text { (almost) instinctive. }\end{array}$} \\
\hline
\end{tabular}

\subsection{Suggested design approach}

In our design process, we approached the problem with a product-service system design. This consists of a physical product that allows spontaneous encounters, encourages joint breaks, and feels relaxing. By using tangible interaction and a separate device, this feels more accessible to make contact, and the feeling of being able to disturb their colleague for social contact disappears.

The second part consists of a service with similar support for remote team building. On the other hand, services, closely integrated with the product, for the onboarding of new employees. The figure below is a schematic representation of this design.

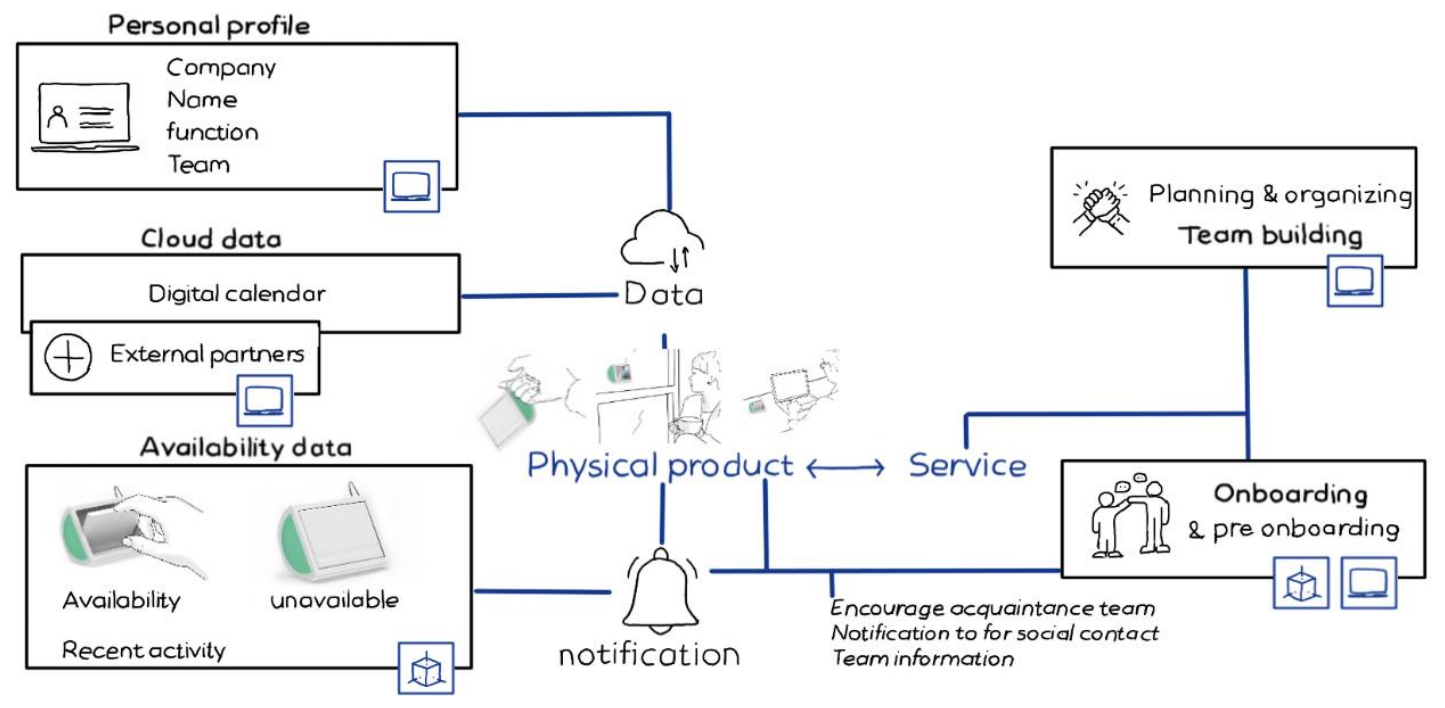




\section{CONCLUSIONS}

We can conclude that there are several opportunities to optimize and enrich the hybrid workplace. Among other things, it is clear that emerging new technologies can play a major role. It is therefore crucial to closely monitor the evolution of these applications in innovation processes. In addition, it is notable that the social context and personal needs are crucial. Therefore, it should be the main focus to be addressed in the design process. Finally, under no circumstances should a future design adversely affect the jobs to be done. On the contrary, innovative processes must contribute to achieving these deeper motivations.

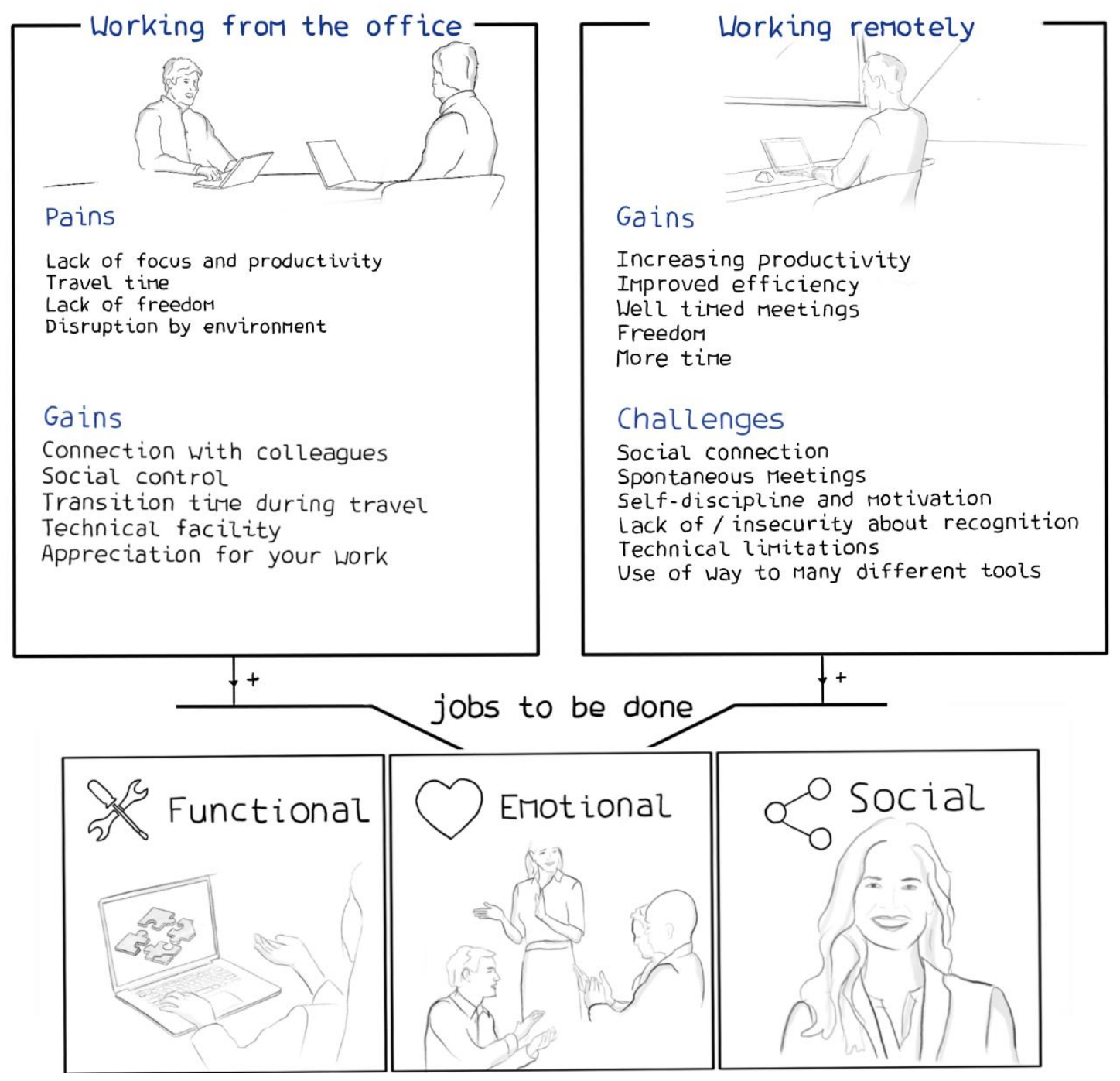

\section{REFERENCES}

[1] Hernandez T. Remote Workers During the COVID-19 Lockdown. What Are We Missing and Why Is Important, 2020, pp.18.

[2] Groenewegen A. Leading Distributed Teams, 2020, pp.36.

[3] Beeckman H. Wat Is De Toekomst Van Telewerk? Hoe Kunnen Bedrijven Het Duurzaam Verankeren Na De Coronacrisis?. Available at: https://www.vrt.be/vrtnws/n1/2020/09/22/telewerk-goed-voor-de-productiviteit-maar-op-langetermijn-houd/ [Accessed on 7 December 2020], (2020) 22 September.

[4] Minten T. Optimaal Digitaal (Samen)Werken: Knelpunten \& Trends - Frankwatching. Available at: https://www.frankwatching.com/archive/2019/06/25/optimaal-digitaal-samenwerkenknelpunten-trends/ [Accessed on 2 December 2020], (2019) 25 June.

[5] Dahik A., Lovich D., Kreafle C., Bailey A., Kilmann J., Kennedy D., Roongta P., Schuler F., 
Tomlin L., and Wenstrup J. What 12,000 Employees Have to Say About The Future Of Remote Work. Available at: https://www.bcg.com/publications/2020/valuable-productivity-gains-covid19 [Accessed on 2020, 3 December 2020], (2020) 11 August.

[6] Sdworx. Corona Doet Vier Op Tien Belgische Bedienden Voor Het Eerst Telewerken. Available at: https://www.sdworx.be/nl-be/pers/2020/2020-05-22-corona-doet-vier-op-tien-belgischebedienden-voor-het-eerst-telewerken [Accessed 11 October 2020], (2020) 22 May.

[7] Wang B., Liu Y., Qian J. and Parker S. Achieving Effective Remote Working During the COVID19 Pandemic: A Work Design Perspective, 2020, pp44.

[8] Bertier L. Five Tech Trends That Will Change Workplace Collaboration In 2020 - ET CIO. Available at: https://cio.economictimes.indiatimes.com/news/corporate-news/five-tech-trendsthat-will-change-workplace-collaboration-in-2020/75025215 [Accessed on 11 December 2020], (2020) 7 April.

[9] Stevens D. Artificial Intelligence Is A Game Changer for Online Meeting Experiences. Available at: https://blog.webex.com/video-conferencing/artificial-intelligence-is-transforming-onlinemeeting-experience/ [Accessed on 11 December 2020], (2019) 20 March. 12] Shen A. Advantages of Artificial Intelligence For Modern Meetings - Unify Square. Available at: https://www.unifysquare.com/blog/advantages-of-artificial-intelligence-for-modern-meetings/ [Accessed 11 December 2020].

[10] Stevens D. The 5 Ways AI Will Transform Team Collaboration. Available at: https://blog.webex.com/team-collaboration/the-5-ways-ai-will-transform-team-collaboration/ [Accessed 6 December 2020], (2019) 26 March.

[11] Soulpage IT Solutions. How AI-Powered Video Conferencing Offering Better Collaborations? Available at: https://soulpageit.com/how-ai-powered-video-conferencing-offering-bettercollaborations/ [Accessed 5 December 2020], (2020) 30 April.

[12] Science of People. How AI Will Revolutionize How We Use Body Language | Science Of People. Available at: https://www.scienceofpeople.com/body-language-ai/ [Accessed 8 December 2020], (2018).

[13] Nichols G. Holographic Collaboration: The Next Big Idea In Remote Work? Available at: https://www.zdnet.com/article/holographic-collaboration-the-next-big-idea-in-remote-work/ [Accessed 5 December 2020], (2020) 3 February.

[14] Foley M. Microsoft's Latest Holoportation Demo Shows Off Its Mixed Reality, AI, Translation Technologies Available at: https://www.zdnet.com/article/microsofts-latest-holoportation-demoshows-off-its-mixed-reality-ai-translation-technologies/ [Accessed 3 December 2020], (2019) 17 July.

[15] Ens B., Lanir J., Tang A., Bateman S., Lee G., Piumsomboon T., and Billinghurst M. Revisiting collaboration through mixed reality: The evolution of groupware, 2019, pp18

[16] Lindberg C., Baranski E., Gilligan B., Fisher J. M., Canada K., Heerwagen J., Kampschroer K., Sternberg E. and Mehl M. R. Personality and Workstation Type Predict Task Focus and Happiness in the Workplace, 2020, pp46.

[17] Javanmard S., Borjali A., Eskandari H. and Farokhi N.A. The structural model of Social Wellbeing in workplace based on Bright-side Personality, Dark Triad and Collectivism Culture, Considering the Mediating Role of Social Influence, 2020, pp49.

[18] Taylor M. Personality Styles: Why They Matter in the Workplace, 2020, pp17.

[19] Tassinari V. Design Als De Creatie Van Een Betekenis - Wanderful.Design. Available at: https://www.wanderful.design/nl/essay/design-als-de-creatie-van-een-betekenis/ [Accessed on 2020, 8 December], (2017) 20 December. 